\title{
BMJ Open Impact of holding the baby following stillbirth on maternal mental health and well-being: findings from a national survey
}

\author{
Maggie Redshaw, Julie M Hennegan, Jane Henderson
}

To cite: Redshaw M, Hennegan JM, Henderson J. Impact of holding the baby following stillbirth on maternal mental health and well-being: findings from a national survey. BMJ Open 2016;6:e010996.

doi:10.1136/bmjopen-2015010996

- Prepublication history and additional material is available. To view please visit the journal (http://dx.doi.org/ 10.1136/bmjopen-2015010996).

Received 27 December 2015 Revised 2 May 2016 Accepted 17 June 2016

CrossMark

Policy Research Unit in Maternal Health \& Care, National Perinatal Epidemiology Unit (NPEU), University of Oxford, Oxford, UK

\section{Correspondence to} Professor Maggie Redshaw; maggie.redshaw@

npeu.ox.ac.uk

\section{ABSTRACT}

Objectives: To compare mental health and well-being outcomes at 3 and 9 months after the stillbirth among women who held or did not hold their baby, adjusting for demographic and clinical differences.

Design: Secondary analyses of data from a postal population survey.

Population: Women with a registered stillbirth in England in 2012.

Methods: 468 eligible responses were compared. Differences in demographic, clinical and care characteristics between those who held or did not hold their infant were described and adjusted for in subsequent analysis. Mental health and well-being outcomes were compared, and subgroup comparisons tested hypothesised moderating factors.

Outcome Measures: Self-reported depression, anxiety, post-traumatic stress disorder (PTSD) symptoms and relationship difficulties.

Results: There was a $30.2 \%$ response rate to the survey. Most women saw $(97 \%, n=434)$ and held $(84 \%, n=394)$ their baby after stillbirth. There were some demographic differences with migrant women, women who had a multiple birth and those whose pregnancy resulted from fertility treatment being less likely to hold their baby. Women who held their stillborn baby consistently reported higher rates of mental health and relationship difficulties. After adjustment, women who held their baby had 2.12 times higher odds ( $95 \% \mathrm{Cl} 1.11$ to 4.04 ) of reporting anxiety at 9 months and 5.33 times higher odds $(95 \% \mathrm{Cl}$ 1.26 to 22.53) of reporting relationship difficulties with family. Some evidence for proposed moderators was observed with poorer mental health reported by women who had held a stillborn baby of $<33$ weeks' gestation, and those pregnant at outcome assessment.

Conclusions: This study supports concern about the negative impact of holding the infant after stillbirth. Results are limited by the observational nature of the study, survey response rate and inability to adjust for women's baseline anxiety. Findings add important evidence to a mixed body of literature.

\section{INTRODUCTION}

Perinatal loss is associated with short-term and long-term consequences for mental

\section{Strengths and limitations of this study}

- The study used data from a population-based sample of women, but the low response rate may have biased findings.

- Women who saw, but did not hold, their baby showed the best self-reported outcomes.

- A wide range of sociodemographic and clinical variables were included, allowing analysis of some moderating factors.

- Very few women did not hold their baby $(n=74)$ and the study sample size was insufficient to assess the impact of some of the proposed moderators.

- Women's choices must be emphasised in practice; further research is needed to provide the best evidence for choices and care.

health and well-being. ${ }^{1-4}$ Clinical guidelines have sought to recommend management practices based on best evidence..$^{5-10}$ However, having contact with the baby after stillbirth remains a controversial aspect of care. ${ }^{11}$ Past National Institute for Health and Clinical Excellence (NICE) guidelines stated that " mothers whose infants are stillborn or die soon after birth should not be routinely encouraged to see and hold the dead infant'. ${ }^{6}$ Recently released guidance responded to criticism of this wording, ${ }^{11}$ suggesting care providers discuss with women 'the option of 1 or more of the following: seeing a photograph of the baby, having mementos of the baby, seeing the baby, holding the baby'. ${ }^{8}$ Qualitative studies have found that parents feel holding the stillborn baby is a valuable and important opportunity to build memories, 'say goodbye' and generate mementoes. ${ }^{5-12-14}$ In contrast, quantitative findings have been mixed, with studies finding negative, ${ }^{15-17}$ positive $^{18}$ and null or mixed effects on mental health. ${ }^{19} 20$

A recent systematic review identified 11 quantitative studies comparing outcomes 
between mothers who held or did not hold their stillborn baby. ${ }^{21}$ Risk of bias appraisal revealed poor study quality. Most studies failed to adjust for potential confounders, and samples were rarely representative. The review reported mixed and inconclusive evidence for an effect of holding the baby on mental health and wellbeing, although women were consistently satisfied with their decision to hold their baby. The review also proposed several factors which may moderate relationships between holding their stillborn baby and outcomes for parents. First, timing of outcome assessment, with the effect of holding hypothesised to decrease over time. ${ }^{15}{ }^{21}$ Second, women's pregnancy status at outcome assessment, or further live births. ${ }^{20}$ The condition of the stillborn baby was an additional moderator identified in qualitative studies ${ }^{1422}$ and may include factors such as infant gestation at the time of stillbirth, the time between antepartum death and the birth and the reason for stillbirth (eg, congenital abnormality). The level of support provided by staff for contact with the infant was also a hypothesised moderator. ${ }^{513-14} 21$

Controversies around interaction with the baby after stillbirth have focused on holding, as almost all parents see their baby. ${ }^{18} 23$ The interpretation typically being that holding has an additional effect beyond seeing the baby. Limited studies support this. ${ }^{16}{ }^{19}$ Holding the baby may represent a more tactile and intimate act than seeing. Quantifying the impact of holding the baby, in contrast to seeing, may provide a more nuanced picture of the specific effect of holding. Guided by the recent review, this study aimed to assess the impact of holding the baby after stillbirth on maternal mental health and well-being.

\section{RESEARCH QUESTIONS}

This study sought to answer the following research questions:

1. How many women saw or held their baby after stillbirth?

2. Who held their baby after stillbirth? Did demographic, clinical or care characteristics differ between the women who held and did not hold their baby?

3. Did mental health and well-being outcomes differ between those who held or did not hold their baby? Were differences significant after adjustment for demographic, clinical and care characteristics?

4. What was the unique impact of holding the baby on mental health and well-being outcomes, in contrast to that attributable to only seeing the baby?

5. Was the impact of contact with the stillborn baby different according to current pregnancy status, or the condition of the baby (captured by time from antepartum death to birth, stillbirth gestation, presence of congenital anomaly)?

\section{METHODS}

Data collection

Secondary analysis was conducted on data from the Listening to Parents survey. ${ }^{24}$ All women aged 16 years and older, who had a registered stillbirth between 1 January and 31 March 2012, or 1 June and 31 August 2012 in England were identified by the Office for National Statistics (ONS) and invited to participate. The ONS defines stillbirths for registration as follows: 'A child that has issued forth from its mother after the 24th week of pregnancy, and that did not at any time after being completely expelled from its mother breathe or show any signs of life' (ref. 25, p. 31). Women were sent an initial letter, followed by a pack containing a letter, study information and a leaflet in 18 non-English languages giving details of how to get help with the survey. These were sent out by ONS between 6 and 9 months after the stillbirth. A reminder and further copy of the questionnaire were posted to non-respondents after 4 weeks. Surveys could be returned by mail completed, or blank if women preferred not to take part. Women could also be interviewed by telephone in their own language. Information about the survey was posted on the website of Sands, a stillbirth support organisation.

\section{Survey instrument}

The Listening to Parents survey asked structured questions capturing the clinical and care experiences of women who had a stillbirth, from pregnancy through to postnatal care. The questionnaire was based on the design of national maternity surveys of women who had a live birth. ${ }^{26-28}$ Women having a stillbirth are generally excluded from such surveys, thus other questions were specifically tailored for this group in addition. Parents and representatives from Sands collaborated throughout the planning and design process to ensure their perspectives were considered.

\section{Measures}

Demographic information collected from women included age, education, ethnicity, partner status and obstetric history. Data from ONS relating to the whole sample included marital status, age group, country of birth and Index of Multiple Deprivation (IMD; an areabased measure using postcode) in quintiles.

Contact with the baby after stillbirth was assessed using a structured question response format with 11 items ranging from seeing their baby to taking them home (full list reported in table 1). Women indicated 'Yes' if they engaged in this activity, 'No, was not offered', 'No, I was not well enough' or 'No, I felt I could not or did not want this'. Descriptive analyses report the reasons women did not engage in each type of contact. Outcome analyses were conducted on two dichotomous variables reflecting whether or not women saw or held their baby.

Psychological and physical well-being after birth was reported through a symptom checklist based on those from national surveys. ${ }^{26}{ }^{29}$ Women were asked 'Did you experience any of the following...' and indicated if the symptom was present 3 months after the birth and in the last few days (median 9 months after birth). Physical and psychological symptoms included poor physical 
Table 1 Proportions of women reporting contact with their baby after stillbirth

\begin{tabular}{|c|c|c|c|c|c|}
\hline \multirow[b]{2}{*}{ Type of contact $(n)$} & \multirow[b]{2}{*}{$\begin{array}{l}\text { Yes } \\
\% \text { (n) }\end{array}$} & \multirow[b]{2}{*}{$\begin{array}{l}\text { No (total) } \\
\%(n)\end{array}$} & \multicolumn{3}{|c|}{ No, with reasons } \\
\hline & & & $\begin{array}{l}\text { Was not } \\
\text { offered this } \\
\%(n)\end{array}$ & $\begin{array}{l}\text { Was not } \\
\text { well enough } \\
\%(n)\end{array}$ & $\begin{array}{l}\text { Felt could not } \\
\text { or did not want to } \\
\%(n)\end{array}$ \\
\hline See baby (468) & $92.7(434)$ & $7.3(34)$ & $0.4(2)$ & $0.6(3)$ & $6.2(29)$ \\
\hline Hold baby (468) & 84.2 (394) & $15.8(74)$ & $1.9(9)$ & $1.5(7)$ & $12.4(58)$ \\
\hline Name baby (467) & 97.0 (453) & $3.0(14)$ & $0.2(1)$ & $0.4(2)$ & $2.4(11)$ \\
\hline Feel able to spend time with baby (466) & $89.1(415)$ & $10.9(51)$ & $0.9(4)$ & $1.7(8)$ & $8.4(39)$ \\
\hline Have photos of baby (467) & $92.5(432)$ & $7.5(35)$ & $0.2(1)$ & $0.2(1)$ & $7.1(33)$ \\
\hline Have other children or relatives see baby (455) & $67.5(307)$ & $32.5(148)$ & $5.7(26)$ & $0.4(2)$ & $26.4(120)$ \\
\hline Dress baby (455) & $46.6(212)$ & $53.4(243)$ & $21.1(96)$ & $4.4(20)$ & $27.9(127)$ \\
\hline Bath baby (444) & $14.6(65)$ & 85.4 (379) & $48.0(213)$ & $5.9(26)$ & $31.5(140)$ \\
\hline Have a lock of baby's hair (433) & $55.9(242)$ & $44.1(191)$ & $26.1(113)$ & $0.7(3)$ & $17.3(75)$ \\
\hline Have a copy of hand or footprints (463) & $92.2(427)$ & $7.8(36)$ & $2.2(10)$ & $0.4(2)$ & $5.2(24)$ \\
\hline Take baby home (448) & $4.5(20)$ & $95.5(428)$ & $52.9(237)$ & $2.7(12)$ & $40.0(179)$ \\
\hline
\end{tabular}

health, palpitations or feelings of panic, depression, anxiety, sleep problems, flashbacks to labour or birth, difficulties in concentrating, relationship difficulties with husband or partner and relationship difficulties with family members (for full list see ref. 30). Outcomes for the present study were selected based on prior literature and hypothesised associations. Physical symptoms, with the exception of a general 'poor physical health', were not included. Symptoms reflecting post-traumatic stress disorder (PTSD) were combined to represent a single 'PTSD symptoms' variable. Women were considered to be displaying PTSD-type symptoms if they reported experiencing two or more of the four symptoms at 3 and 9 months; 'palpitations or feelings of panic', 'sleep problems', 'flashbacks to labour or birth' and 'difficulties in concentrating'.

Women's care experiences were assessed through structured items. Women were asked to report whether they agreed, disagreed or were unsure regarding the statements 'Staff treated me as an individual' and 'Staff gave me the care I needed' in their care after birth. Overall quality of postnatal care was assessed through a 5-point Likert scale from 1 (very satisfied) to 5 (very dissatisfied), with a midpoint of 'neither satisfied nor dissatisfied'.

\section{Analyses}

Analyses were conducted using SPSS V.22. Bivariate analysis using the $\chi^{2}$ statistic compared women who held or did not hold their baby on demographic, clinical and care characteristics. Where significant differences were identified $(\mathrm{p}<0.05)$, these were adjusted for in subsequent outcome analyses. Multiple logistic regressions were used to adjust for differences between the two groups, namely multiple pregnancy, fertility treatment and ethnic minority status. While being born outside the UK also differed, there was substantial overlap with ethnicity and only one characteristic was included to avoid collinearity. The time between antepartum death and the birth also differed between those who held and did not hold their baby. This was investigated through subgroup analyses as a hypothesised moderator.

Bivariate analyses using the $\chi^{2}$ statistic described outcomes individually for those who held (and therefore also saw) their baby, only saw their baby and neither saw nor held their baby to quantify the impact of holding in comparison to seeing the baby. Multiple logistic regressions were conducted including holding (compared with not holding) and seeing (compared with not seeing) the baby (as well as demographic adjustments) with ORs reported for comparison between seeing and holding the baby. Subgroup analyses capturing hypothesised moderators $^{21}$ were conducted where data were available and included current pregnancy status and the condition of the baby (time between antepartum death and the birth, gestation at stillbirth and congenital anomaly).

\section{RESULTS}

\section{Respondents}

A total of 474 women completed and returned the stillbirth questionnaire, a response rate of $30.2 \%$. Two women completed the survey over the phone with the help of an interpreter. A full comparison of respondents and non-respondents is provided elsewhere. ${ }^{24}$ Compared with respondents, women who chose not to take part were more likely to have been born outside the UK, to be aged $<30$, and to live in a more deprived area. ${ }^{24}$ Of those who participated, 468 answered questions about holding their stillborn baby and if they were experiencing depression or anxiety 9 months after birth. Thus a total sample of 468 was included in the present study. Demographic characteristics are presented according to whether or not women had contact with their baby.

\section{How many women had contact with their baby?}

The proportion of women who had different types of contact with their baby after stillbirth and reasons for not doing so are shown (table 1). A total of $92.7 \%$ of women saw their baby and $84.2 \%$ held their baby. Many 
took or had photos taken of their baby $(92.5 \%)$. Few women bathed their baby $(14.6 \%)$ or took their baby home $(4.5 \%)$. For most women who did not see or hold their baby, this was because they could not or did not want to, rather than because it was not offered.

\section{Who held their baby after stillbirth?}

The proportion of women who held or did not hold their baby are presented in table 2 according to measured demographic, clinical and care characteristics. Women who had a multiple birth, were born outside the UK or self-identified as black or minority ethnic (BME) group were less likely to have held their baby. There were few statistically significant clinical differences, although women whose pregnancy resulted from fertility treatment were significantly less likely to have held their baby. The time between antepartum death and birth also influenced contact with the baby. Women whose baby died in the hours before birth or during birth were more likely to hold their baby than other groups $\left(\chi^{2}(1)\right.$ $=8.99, \mathrm{p}=0.003)$. Self-reported experiences of care, including being treated as an individual, receiving the care needed and overall satisfaction, were not associated with holding the baby. Additional comparisons were conducted to assess if differences according to ethnicity represented care inequality. Of those who did not hold their baby, $81.3 \%$ of BME women and $77.6 \%$ of white women reported that this was because they could not or did not want to, a further $18.8 \%$ of ethnic minority women, and only $6.9 \%$ of white women reported not being well enough to do so. No BME women reported that they were not offered the opportunity to hold their stillborn baby.

\section{What was the impact of holding the baby on mental health and well-being outcomes?}

The rates of self-reported depression and anxiety were high 3 months after birth $(43.4 \%, 39.3 \%)$, and lower, but still pronounced, at 9 months $(24.1 \%, 30.3 \%)$. At 3 and 9 months, respectively, half $(51.1 \%)$ and over a third $(35.9 \%)$ of women reported two or more PTSD-type symptoms. At these time points, some (31.2\% and $48.3 \%$ ) reported no PTSD-type symptoms and $17.7 \%$ and $15.8 \%$ reported only one symptom. Fewer women $(20.9 \%$ and $12.4 \%)$ reported three symptoms, though some (13.2\% and $7.9 \%)$ reported all four symptoms. With the exception of physical health, all outcomes show a trend towards higher prevalence in those who held their baby compared with those who did not (table 3). Self-reported depression did not differ significantly between the groups at either time (table 3). Women who held their baby after birth were more likely to report anxiety at 3 months $(41.4 \%)$ than women who did not $(28.4 \%)$, although this difference was not significant after adjustment for demographic and clinical factors. Anxiety at 9 months remained significantly more common among those who held their baby, even after adjustment. PTSD-type symptoms were significantly more common at 3 and 9 months for those who held their baby, although this difference was no longer significant after adjustment. Broad CIs should be noted, but both approached significance at the two time points. Relationship difficulties with partners were reported by $\sim 17 \%$ of women at 3 months, and $9 \%$ at 9 months, with similar prevalence for those who held and did not hold their baby. Relationship difficulties with families, however, were more prevalent at 3 and 9 months for those who held their baby after stillbirth and remained significant after adjustment at 9 months.

\section{What was the contribution of seeing, in contrast to holding, the baby on outcomes?}

A total of 40 women saw, but did not hold their baby, and 34 women neither saw nor held their baby. Individual associations between holding (and seeing), seeing alone and neither seeing nor holding the baby and prevalence of mental health and well-being outcomes are shown (table 4). Mothers who held their baby and those who neither saw nor held their baby had consistently poorer outcomes than those who only saw their baby. Adjusted ORs for final models of outcomes which include seeing (compared with not seeing) and holding (compared with not holding) as well as demographic and clinical adjustments are presented (table 4).

All significant associations with holding were maintained with effect sizes increasing. The odds of experiencing anxiety for those who held their stillborn were increased from 1.86 to 3.80 (1.55 to 9.35) at 3 months, and 2.26 to 4.29 (1.49 to 12.38) at 9 months. Broad CIs should be noted with the introduction of seeing the baby into the model, likely due to the very small proportion of women who did not see their baby. Seeing the baby showed a consistent trend to decrease the odds of negative outcomes across primary and secondary outcomes. Women who saw their baby had significantly lower odds of reporting anxiety at $3(0.19)$ and $9(0.27)$ months (table 4).

\section{Does the impact of holding the infant differ according to proposed moderators? Current pregnancy status}

For women who were and were not pregnant at the time of survey, negative outcomes were more prevalent among those who held their baby (see online supplementary materials table A). However, current pregnancy was associated with increased odds of PTSD-type symptoms remaining significant among those who were currently pregnant, with no significant associations between holding and mental health and well-being outcomes for those who were not currently pregnant.

\section{Condition of the baby}

The small numbers of women who did not hold their baby and small subgroup sizes (eg, congenital anomaly, 59 women) severely limit the reliability of subgroup analyses. However, trends across outcome measures provide some estimation of possible subgroup effects. Outcomes 
Table 2 Demographic, clinical and care characteristics of those who held or did not hold their baby

\begin{tabular}{|c|c|c|}
\hline & $\begin{array}{l}\text { Held \% } \\
\text { (n) } \\
N=394\end{array}$ & $\begin{array}{l}\text { Did not } \\
\text { hold \% (n) } \\
\mathrm{N}=74\end{array}$ \\
\hline \multicolumn{3}{|c|}{ Demographic characteristics (n) } \\
\hline \multicolumn{3}{|c|}{ Maternal age (years) $(464)(p=0.114)$} \\
\hline $16-19$ & $75.0(9)$ & $25.0(3)$ \\
\hline 20-29 & $89.5(145)$ & $10.5(17)$ \\
\hline 30-39 & $81.1(202)$ & $18.9(47)$ \\
\hline $40+$ & $82.9(34)$ & $17.1(7)$ \\
\hline \multicolumn{3}{|c|}{ Age on leaving full-time education (years) $(458)(p=0.322)$} \\
\hline$<17$ & $86.7(65)$ & $13.3(10)$ \\
\hline $17-18$ & $87.4(125)$ & $12.6(18)$ \\
\hline $19+$ & $82.1(197)$ & $17.9(43)$ \\
\hline \multicolumn{3}{|l|}{ Ethnicity $(466)^{\star \star}(p=0.013)$} \\
\hline White & $85.6(351)$ & $14.2(58)$ \\
\hline Black/Asian/mixed/other & $71.9(41)$ & $28.1(16)$ \\
\hline \multicolumn{3}{|c|}{ Maternal country of birth $(466)^{\star \star \star}(p<0.001)$} \\
\hline UK & $87.3(336)$ & $12.7(49)$ \\
\hline Outside the UK & $70.4(57)$ & $29.6(24)$ \\
\hline \multicolumn{3}{|c|}{ Index of Multiple Deprivation quintiles (464) $(p=0.056)$} \\
\hline $\begin{array}{l}\text { 1st quintile (most } \\
\text { disadvantaged) }\end{array}$ & $79.3(84)$ & $20.8(22)$ \\
\hline 2nd quintile & $81.3(74)$ & $18.7(17)$ \\
\hline 3rd quintile & $87.5(77)$ & $12.5(11)$ \\
\hline 4th quintile & $88.3(83)$ & $11.7(11)$ \\
\hline $\begin{array}{l}\text { 5th quintile (most } \\
\text { advantaged) }\end{array}$ & $87.1(74)$ & $12.9(11)$ \\
\hline \multicolumn{3}{|c|}{ Partnership status (468) $(p=0.869)$} \\
\hline Married or with partner & $84.4(357)$ & $15.6(66)$ \\
\hline Single mother & $82.2(37)$ & $17.8(8)$ \\
\hline \multicolumn{3}{|c|}{ Long term physical problem (464) $(p=0.171)$} \\
\hline No & $84.1(382)$ & $15.9(72)$ \\
\hline Yes & $100(10)$ & $0(0)$ \\
\hline \multicolumn{3}{|c|}{ Long term mental health problem $(462)(p=0.578)$} \\
\hline No & $84.6(374)$ & $15.4(68)$ \\
\hline Yes & $80.0(16)$ & $20.0(4)$ \\
\hline \multicolumn{3}{|l|}{ Clinical characteristics (n) } \\
\hline \multicolumn{3}{|c|}{ Multiple births $(463)^{\star \star}(p=0.008)$} \\
\hline Singleton & $85.7(372)$ & $14.3(62)$ \\
\hline Multiple & $65.5(19)$ & $34.5(10)$ \\
\hline \multicolumn{3}{|l|}{ Parity $(467)(p=0.913)$} \\
\hline Primiparous & $84.0(231)$ & $16.0(44)$ \\
\hline Multiparous & $84.4(162)$ & $15.6(30)$ \\
\hline \multicolumn{3}{|c|}{ Experienced previous pregnancy loss $(466)(p=0.068)$} \\
\hline No & $82.2(273)$ & $17.8(59)$ \\
\hline $\begin{array}{l}\text { Yes (miscarriage, late } \\
\text { miscarriage, termination, } \\
\text { stillbirth or neonatal death }\end{array}$ & $89.6(120)$ & $10.4(14)$ \\
\hline \multicolumn{3}{|c|}{ Pregnancy the result of fertility treatment $(461)^{*}(p=0.018)$} \\
\hline No & $85.4(369)$ & $14.6(63)$ \\
\hline Yes & $69.0(20)$ & $31.0(9)$ \\
\hline \multicolumn{3}{|c|}{ Gestation at stillbirth $(454)(p=0.122)$} \\
\hline 24-28 weeks & $81.6(84)$ & $18.4(19)$ \\
\hline 29-32 weeks & $85.5(53)$ & $14.5(9)$ \\
\hline 33-36 weeks & $78.7(74)$ & $21.3(20)$ \\
\hline $37+$ weeks & $88.7(173)$ & $11.3(22)$ \\
\hline
\end{tabular}

Continued
Table 2 Continued

$\begin{array}{ll}\text { Held \% } & \text { Did not } \\ (n) & \text { hold \% (n) } \\ \mathrm{N}=394 & \mathrm{~N}=74\end{array}$

Time between antepartum death and the birth $(454)^{\star}$ $(\mathrm{p}=0.011)$

1 or more weeks before birth $81.8(72) \quad 18.2(16)$

Few days before birth $\quad 81.0(132) 19.0$ (31)

The day before birth $\quad 87.7$ (57) 12.3 (8)

Hours before or during birth $94.8(92) \quad 5.2(5)$

Unsure

$75.6(31) \quad 24.4(10)$

Type of birth (447) $(p=0.238)$

$\begin{array}{lcc}\text { Vaginal } & 84.6(325) & 15.4(59) \\ \text { Caesarean } & 77.8(49) & 22.2(14) \\ \text { Congenital anomaly (451) } & (\mathrm{p}=0.680) & \\ \text { No } & 84.4(331) & 15.6(61) \\ \text { Yes } & 81.4(48) & 18.6(11)\end{array}$

Care experience after stillbirth

Staff treated me as an individual (463) $(p=0.353)$

Agree $\quad 84.9$ (349) $15.1(62)$

Disagree/not sure $\quad 78.8(41) \quad 21.2(11)$

Staff gave me the care I needed $(460)(p=0.414)$

Agree $\quad 85.0$ (345) 15.0 (61)

Disagree/not sure $\quad 79.6(43) \quad 20.4$ (11)

Overall satisfaction with the care received after baby had died (463) $(p=0.428)$

Very satisfied $\quad 85.9(152) 14.1(25)$

Satisfied $\quad 81.6(115) \quad 18.4(26)$

Neither satisfied nor $\quad 88.9$ (64) 11.1 (8)

dissatisfied

Dissatisfied $\quad 84.6(33) \quad 15.4(6)$

Very dissatisfied $76.5(26) \quad 23.5(8)$

${ }^{*} p<0.05 ;{ }^{* *} p<0.01 ;{ }^{* * *} p<0.001$.

are presented according to proposed moderators in online supplementary materials table B.

The association between holding the baby and poor mental health and well-being outcomes was consistent across all baby characteristics reflecting the condition of the baby at the time of holding (time between antepartum death and the birth, gestation, presence of congenital anomaly). Effect sizes were larger for those with a stillbirth of less than 33 weeks' gestation. While there were some differences in the prevalence of negative mental health and well-being outcomes across subgroups reflecting the condition of the baby, few were statistically significant. Anxiety was higher in those whose baby died prior to the day of the birth. Small sample sizes and broad CIs caution against overinterpretation of results; however, these analyses suggest that the negative effects of holding may be increased for mothers whose baby is likely to be in poorer physical condition.

\section{DISCUSSION}

\section{Main findings}

Most women saw (97\%) and held their baby (84\%), with those not doing so mainly reporting that this was 
Table 3 Impact of holding the stillborn baby on mental health and well-being

\begin{tabular}{|c|c|c|c|c|}
\hline & $\begin{array}{l}\text { Held \% (n) } \\
\mathrm{N}=394\end{array}$ & $\begin{array}{l}\text { Did not hold \% (n) } \\
\mathrm{N}=74\end{array}$ & OR $(95 \% \mathrm{Cl})$ & $\mathrm{OR}_{\mathrm{adj}}(95 \% \mathrm{Cl})$ \\
\hline \multicolumn{5}{|c|}{ Mental and physical health 3 months after birth $(n=468)$} \\
\hline Depression $(p=0.358)$ & $44.4(175)$ & $37.8(28)$ & $1.31(0.78$ to 2.20$)$ & 1.21 (0.71 to 2.07$)$ \\
\hline Anxiety $^{*}(p=0.049)$ & $41.4(163)$ & $28.4(21)$ & $1.86^{*}(1.07$ to 3.24$)$ & $1.64(0.93$ to 2.90$)$ \\
\hline PTSD symptoms ${ }^{\star \star}(p=0.009)$ & $53.8(212)$ & $36.5(27)$ & $1.93^{*}(1.15$ to 3.24$)$ & $1.70(0.99$ to 2.90$)$ \\
\hline Poor physical health $(p=0.485)$ & $12.4(49)$ & $16.2(12)$ & 0.70 (0.35 to 1.40$)$ & $0.72(0.34$ to 1.48$)$ \\
\hline \multicolumn{5}{|c|}{ Mental and physical health 9 months after birth $(n=468)$} \\
\hline Depression $(p=0.112)$ & $25.6(101)$ & $16.2(12)$ & $1.71(0.88$ to 3.31$)$ & $1.65(0.84$ to 3.24$)$ \\
\hline Anxiety $^{*}(p=0.014)$ & 32.7 (129) & $17.6(13)$ & $2.26^{*}(1.19$ to 4.27$)$ & $2.12^{*}(1.11$ to 4.04$)$ \\
\hline PTSD symptoms $^{*}(\mathrm{p}=0.017)$ & $38.3(151)$ & $23.0(17)$ & $2.01^{*}(1.13$ to 3.61$)$ & 1.77 (0.98 to 3.21$)$ \\
\hline Poor physical health $(p=0.541)$ & $4.3(17)$ & $6.8(5)$ & $0.73(0.24$ to 2.25$)$ & $0.91(0.28$ to 2.96$)$ \\
\hline \multicolumn{5}{|c|}{ Relationship difficulties 3 months after birth } \\
\hline With partner $(p=0.699)$ & $17.5(69)$ & $14.9(11)$ & $1.20(0.60$ to 2.39$)$ & 1.07 (0.53 to 2.17$)$ \\
\hline With family $(p=0.056)$ & $22.8(90)$ & $12.2(9)$ & $2.11^{*}(1.01$ to 4.41$)$ & $1.98(0.94$ to 4.18$)$ \\
\hline \multicolumn{5}{|c|}{ Relationship difficulties 9 months after birth } \\
\hline With partner $(\mathrm{p}=0.999)$ & $8.9(35)$ & $8.1(6)$ & 1.09 (0.44 to 2.69$)$ & $1.03(0.41$ to 2.58$)$ \\
\hline With family ${ }^{*}(p=0.012)$ & $14.0(55)$ & $2.7(2)$ & $5.77^{\star}(1.37$ to 24.21$)$ & $5.33^{*}(1.26$ to 22.53$)$ \\
\hline
\end{tabular}

because they felt they could not, or did not wish to do so $(78 \%)$. Few measured demographic, clinical and care characteristics differed between those who held and did not hold their baby, comparable to past research. ${ }^{20}$ Women whose pregnancy was the result of fertility treatment, who had a multiple birth or were born outside the UK (ie, ethnic minority status) were significantly less likely to have held their baby. Women whose pregnancy resulted from treatment for infertility were more likely to have also experienced a multiple birth and a more complex birth, which may account for some of this difference. All women with multiple births were included in the survey irrespective of how many of the babies died, which may also have reduced the rate of contact in this group. Further analysis suggested lower rates of holding for ethnic minority women were due to personal preferences and poorer health after stillbirth, consistent with past evidence, ${ }^{31} 32$ rather than differences in care practices. The quality of interpersonal care ratings did not differ significantly between those who held and did not hold their stillborn baby. Of those who reported feeling they were treated as an individual and given the care they needed, there was a slightly higher proportion holding their baby. Items did not capture care specifically related to holding the baby after stillbirth, such as staff support for this behaviour or how the baby was presented to them, which may have differed. As qualitative studies have found, the nature of the care provided, contextual factors and other interaction with the baby after stillbirth contribute to a nuanced and complex experience, which must be considered in interpreting findings and making practice recommendations. ${ }^{33}$

Holding the stillborn baby was associated with a trend towards poorer mental health and relationship outcomes.
After adjustment, anxiety and relationship difficulties at 9 months were significantly higher in women who had held their baby. For those who were pregnant at the time of the survey, PTSD-type symptoms were significantly higher at 3 and 9 months, and both PTSD symptoms and depression were significantly more common in those who held a stillborn of $<33$ weeks' gestation, even after adjustment. Other differences were not statistically significant or did not remain so after adjustment.

Study findings are in some conflict with qualitative reports and quantitative assessments of satisfaction with holding the stillborn baby, which suggest parents believe the experience to be beneficial and are pleased with their decision to do so. ${ }^{512-14}{ }^{21}$ Findings are consistent with those of Hughes and Turton ${ }^{15} 16$ who found that women who held their baby had a higher likelihood of PTSD. The present study did not find any effects on relationships with partners, identified previously, ${ }^{15}$ but did find relationship difficulties with families to be more frequent among those who held their baby. One possible explanation for these findings is that while physical contact is valued by parents, it provides more distressing images and recollections of the baby who was stillborn, contributing to trauma, re-experiencing and anxiety in later months and years. This may be consistent with findings from systematic reviews that more memories of a traumatic event or revisiting the traumatic event through debrief counselling is associated with higher levels of PTSD. ${ }^{15}$ 34-36

An assessment of the role of seeing the baby revealed the most positive outcomes for women who saw, but did not hold, their baby, while women who neither saw nor held their baby showed more adverse outcomes. This effect was further demonstrated with both seeing and 
Table 4 Associations between holding, seeing alone and neither seeing nor holding and outcomes



holding modelled as predictors of outcomes, with seeing demonstrating consistently positive effects and holding more pronounced negative effects after adjustment. This provides some support for the assertion that the additional physical interaction with the baby involved in holding invokes anxiety. However, it should be noted that very few women saw but did not hold their baby $(n=40)$, or neither saw nor held their baby $(n=34)$. Small sample sizes and broad CIs suggest results must be interpreted with caution.

Analysis of proposed moderators was limited by small group sizes. The study found consistent negative relationships between holding the baby and outcomes, irrespective of pregnancy status at the time of survey, in contrast to past research. ${ }^{20}$ Many of these relationships were not significant in subgroup analyses which may indicate a lack of effect, or be due to limited power as raw percentages differed substantially. Results provide some support for suggestions from qualitative studies that poor condition of the baby (such as early gestation or longer time between antenatal death and birth) may be confronting, ${ }^{14} 22$ intensifying any negative impact of holding the baby.

Strengths and limitations

This study is the largest to date, assessing the impact of holding the baby on mental health and well-being of 
mothers. Survey data included a wide range of demographic, clinical and care characteristics, which could be compared and adjusted in analyses. Although limited by subgroup numbers, the study was the most comprehensive yet in the assessment of potential moderators. The population-based data collection avoided the bias of individual site or online-based responses and sought to be representative by surveying all women; however, the low response rate limits the generalisability of findings. It is possible that these women had different experiences which were not captured in this survey. Women with poorer emotional and mental health may have been more or less likely to respond. The cross-sectional and observational nature of the data is also limiting. Causal inferences cannot be drawn and unmeasured variables may be responsible for the associations identified. For example, it may be the case that women with less anxiety were more likely to choose not to hold their baby. Incorporating an assessment of prepregnancy mental health would be a valuable addition to future research; however, prospective evaluations through large cohort studies would struggle to have sufficient sample size of women who fall pregnant and experience a stillbirth. Those with poorer relationships with their family may also have been less likely to hold their baby. As in many observational studies, unmeasured confounders may have driven observed relationships. Interestingly, significant effects were observed at 9 months after the birth (the time of survey), but not at 3 months. Given the high rate of poor mental health reported at 3 months, it may be that the effect of holding is only evident after this time period. It may also indicate bias in reporting for questions asked retrospectively about how women felt 6 months earlier, in contrast to asking how they have felt in the past few days.

While the large sample was a strength, the study still lacked power as most women held their baby. The timing of data collection, around 9 months after stillbirth, represents a relatively proximal time point when feelings about loss are still likely to be intense. Analyses were carried out in accordance with an established plan based on the findings of a recent review undertaken by the authors, and all conducted analyses have been reported. While this minimises reporting bias, it does not mitigate the possibility for error introduced by conducting a large number of comparisons.

Results are limited by the use of single-item selfreported depression, anxiety and 4-item PTSD-type symptoms rather than validated measures. However, these measures had high face validity and were the best available in the survey for secondary analysis. Comparison data from cohort studies of surviving infants suggest that at around 9 months rates of depression among mothers are less than half the rate reported by mothers who experienced a stillbirth of their baby. ${ }^{29}$ 37-39

\section{Interpretation}

The present study suggests that holding the stillborn baby may negatively affect maternal mental health and well-being. As recent review has suggested, evidence for this practice is mixed. ${ }^{21}$ This study highlights the need for larger, longer-scale studies to investigate this aspect of care. The work is the most comprehensive to date in adjusting for potential confounders and considering the role of subgroups, which can be further explored in future research. Moving forward, studies should also investigate the role of individual differences which may account for the mixed results found to date. Further, the mechanisms underlying any detrimental effects of holding should be identified. Factors such as the duration of holding, type of contact, exposure to a deteriorating state of the baby and the way in which support is provided at this time may all contribute to the identified effects. The finding that seeing may have a protective effect, in contrast to holding, warrants further investigation. The consistent finding that women are satisfied with their decision to hold the baby ${ }^{21}$ must be kept in mind when interpreting the findings of this study. Results highlight the need for further research to provide women and care providers with evidence with which to make decisions at this time. The findings should not provoke prescriptive practices which negate women's choices. More fundamentally, the findings also highlight a need for research on the immediate and longer term outcomes and support needs of this whole population of women who are clearly affected by the psychological and social costs of the stillbirth of their baby. ${ }^{40}$

\section{Conclusion}

This study supports the findings of Turton and Hughes ${ }^{15}{ }^{16}$ finding that holding the stillborn baby was associated with a trend towards poorer mental health outcomes, particularly anxiety. Seeing the baby, in contrast, demonstrated a protective effect on mental health. Results should be interpreted with caution given study design: secondary analysis of survey findings with a low response rate. Many associations were not statistically significant after adjustment for demographic and clinical differences, broad CIs were observed and only a small proportion of women did not hold their baby. Findings emphasise the need for further research to clarify the way in which care and contact with their stillborn baby affects mothers and impacts in the longer term, in order to better to inform policy and practice recommendations while at the same time providing women with the opportunity to make informed decisions and respecting their autonomy.

Acknowledgements The authors give their particular thanks to the women and their families who completed the survey and to the 10 bereaved mothers who helped develop the questionnaire and study materials. The authors are grateful to Charlotte Bevan, Janet Scott, Sue Hale and Judith Schott; Patrick Wilcockson and the helpline staff at Sands; Farrah Pradhan and Carmel Barrett at Bliss; Rachel Rowe, Jenny Kurinczuk and Marian Knight from the National Perinatal Epidemiology Unit, for their assistance in development of the materials and supporting the survey. Mark Gautrey and staff at the Office for National Statistics were responsible for drawing the sample and managing the mailings. The authors also thank Jenny Kurinczuk for commenting on the manuscript. 
Contributors MR proposed the work. MR with Rachel Rowe designed the Listening to Parents survey. MR and JH were involved in data collection, management and cleaning. MR, JMH and JH planned the analyses. JMH conducted all analyses and drafted the manuscript. All authors provided feedback on research questions and the manuscript. All authors have read and approved the final manuscript.

Funding This paper reports on an independent study which is funded by the Policy Research Programme in the Department of Health. The views expressed are not necessarily those of the Department of Health.

Competing interests None declared.

Ethics approval The survey was approved by Oxford A Research Ethics Committee ref: 12/SC/0322.

Provenance and peer review Not commissioned; externally peer reviewed.

Data sharing statement The sensitive data collected are not available for data sharing.

Open Access This is an Open Access article distributed in accordance with the Creative Commons Attribution Non Commercial (CC BY-NC 4.0) license, which permits others to distribute, remix, adapt, build upon this work noncommercially, and license their derivative works on different terms, provided the original work is properly cited and the use is non-commercial. See: http:// creativecommons.org/licenses/by-nc/4.0/

\section{REFERENCES}

1. Harper M, O'Connor RC, O'Carroll RE. Increased mortality in parents bereaved in the first year of their child's life. BMJ Support Palliat Care 2011;1:306-9.

2. Kelley MC, Trinidad SB. Silent loss and the clinical encounter: parents' and physicians' experiences of stillbirth-a qualitative analysis. BMC Pregnancy Childbirth 2012;12:137.

3. Christiansen DM, Elklit A, Olff M. Parents bereaved by infant death: PTSD symptoms up to 18 years after the loss. Gen Hosp Psychiatry 2013;35:605-11.

4. Mills TA, Ricklesford C, Cooke A, et al. Parents' experiences and expectations of care in pregnancy after stillbirth or neonatal death: a metasynthesis. BJOG 2014;121:943-50.

5. Downe S, Schmidt E, Kingdon C, et al. Bereaved parents' experience of stillbirth in UK hospitals: a qualitative interview study. BMJ Open 2013;3:pii: e002237.

6. National Institute for Health and Clinical Excellence (NICE). Antenatal and postnatal mental health. London: NICE, 2007.

7. National Institute for Health and Clinical Excellence (NICE) Routine postnatal care of women and their babies. London: NICE, 2006.

8. National Institute for Health and Clinical Excellence (NICE) Antenatal and postnatal mental health: clinical management and service guidance. [CG192]. London: NICE Guidelines, 2014

9. Royal College of Obstetricians and Gynaecologists (RCOG). The RCOG Green-top Guideline No.55 Late Intrauterine Fetal Death and Stillbirth. 2010. https://www.rcog.org.uk/globalassets/documents/ guidelines/gtg_55.pdf (accessed Dec 2015).

10. Queensland Maternity and Neonatal Clinical Guidelines(QMNCG). Stillbirth care. Queensland: Queensland Government, 2011. Contract No.: MN11.24-V4-R16.

11. Cunningham KA. Holding a stillborn baby: does the existing evidence help us provide guidance? Med J Aust 2012;196:558.

12. Gold KJ, Dalton VK, Schwenk TL. Hospital care for parents after perinatal death. Obstet Gynecol 2007;109:1156-66.

13. Erlandsson $\mathrm{K}$, Warland J, Cacciatore J, et al. Seeing and holding a stillborn baby: mothers' feelings in relation to how their babies were presented to them after birth-Findings from an online questionnaire. Midwifery 2013;29:246-50.

14. Ryninks K, Roberts-Collins C, McKenzie-McHarg K, et al. Mothers' experience of their contact with their stillborn infant: an interpretative phenomenological analysis. BMC Pregnancy Childbirth 2014;14:203.

15. Turton P, Evans C, Hughes P. Long-term psychosocial sequelae of stillbirth: phase II of a nested case-control cohort study. Arch Womens Ment Health 2009;12:35-41.
16. Hughes $P$, Turton $P$, Hopper $E$, et al. Assessment of guidelines for good practice in psychosocial care of mothers after stillbirth: a cohort study. Lancet 2002;360:114-18.

17. Turton $P$, Hughes $P$, Evans $C$, et al. Incidence, correlates and predictors of post-traumatic stress disorder in the pregnancy after stillbirth. Br J Psychiatry 2001;178:556-60.

18. Gravensteen IK, Helgadottir LB, Jacobsen EM, et al. Women's experiences in relation to stillbirth and risk factors for long-term post-traumatic stress symptoms: a retrospective study. BMJ Open 2013;3:e003323.

19. Cacciatore J, Rådestad I, Frederik Frøen J. Effects of contact with stillborn babies on maternal anxiety and depression. Birth 2008;35:313-20.

20. Raadestad I, Surkan PJ, Steineck G, et al. Long-term outcomes for mothers who have or have not held their stillborn baby. Midwifery 2009;25:422-9.

21. Hennegan J, Redshaw M, Henderson J. Contact with the baby following stillbirth and parental mental health and well-being: a systematic review. BMJ Open 2015;5:e008616.

22. Sun J-C, Rei W, Sheu S-J. Seeing or not seeing: Taiwan's parents' experiences during stillbirth. Int J Nurs Stud 2014;51:1153-9.

23. Crawley R, Lomax S, Ayers S. Recovering from stillbirth: the effects of making and sharing memories on maternal mental health. J Reprod Infant Psychol 2013;31:195-207.

24. Redshaw M, Rowe R, Henderson J. Listening to Parents after stillbirth or the death of their baby after birth. Oxford: National Perinatal Epidemiology Unit, 2014.

25. Office for National Statistics (ONS). Births statistics: metadata. London: Office for National Statistics, 2015.

26. Redshaw M, Rowe R, Hockley C, et al. Recorded delivery: a national survey of women's experience of maternity care 2006: National Perinatal Epidemiology Unit NPEU; 2007. https://www. npeu.ox.ac.uk/downloads/files/reports/Maternity-Survey-Report.pdf (accessed Nov 2015)

27. Declercq ER, Sakala C, Corry MP, et al. Listening to mothers II: report of the second national U.S. survey of women's childbearing experiences. J Perinat Educ 2007;16:9.

28. Dzakpasu S, Kaczorowski J, Chalmers B, et al. The Canadian maternity experiences survey: design and methods. J Obstet Gynaecol Can 2008;30:207-16.

29. Redshaw M, Henderson J. Safely delivered: a national survey of women's experience of maternity care 2014. Oxford: The National Perinatal Epidemiology Unit, 2014. https://www.npeu.ox.ac.uk/ maternity-surveys

30. Listening to Parents. Listening to parents: women's experience of care in the context of pregnancy loss and neonatal death survey. 2014. https://wwwnpeuoxacuk/listeningtoparents

31. Bollini P, Pampallona S, Wanner $\mathrm{P}$, et al. Pregnancy outcome of migrant women and integration policy: a systematic review of the international literature. Soc Sci Med 2009;68:452-61.

32. Hennegan J, Redshaw M, Kruske S. Another country, another language and a new baby: a quantitative study of the postnatal experiences of migrant women in Australia. Women Birth 2015;28: e124-33.

33. Kingdon C, O'Donnell E, Givens J, et al. The role of healthcare professionals in encouraging parents to see and hold their stillborn baby: a meta-synthesis of qualitative studies. PLOS ONE 2015;10: e0130059.

34. Rose S, Bisson J, Churchill R, et al. Psychological debriefing for preventing post traumatic stress disorder (PTSD). Cochrane Database Syst Rev 2002;2:CD000560.

35. Sijbrandij M, Olff M, Reitsma JB, et al. Emotional or educational debriefing after psychological trauma: randomised controlled trial. Br J Psychiatry 2006;189:150-5.

36. Gil S, Caspi Y, Ben-Ari IZ, et al. Does memory of a traumatic event increase the risk for posttraumatic stress disorder in patients with traumatic brain injury? A prospective study. Am J Psychiatry 2005;162:963-9.

37. Evans J, Heron J, Francomb $\mathrm{H}$, et al. Cohort study of depressed mood during pregnancy and after childbirth. BMJ 2001;323:257-60.

38. Evans J, Melotti R, Heron J, et al. The timing of maternal depressive symptoms and child cognitive development: a longitudinal study. J Child Psychol Psychiatry 2012;53:632-40.

39. Dex S, Joshi H. Children of the 21st century: from birth to nine months: Policy Press; 2005.

40. Heazell AE, Siassakos D, Blencowe $H$, et al. Stillbirths: economic and psychosocial consequences. Lancet 2016;387:604-16. 